\title{
Factors Influence Employee Engagement Leveraging by Organisational culture (Pilot study in Libyan banking sector):
}

\author{
Patrick Mclaughlin, Ahmed Al ashaab, Hamad Rashid \\ Cranfield University, United Kingdom
}

\begin{abstract}
The concept of organizational culture has been a subject of growing interest among many scholars owing to its impact in promoting engagement and organisational performance. Yet it still lacks sufficient application in the Arab world where sociocultural dynamics based on Islam tend to be unique in comparison to the western world. In Libya, this has been further complicated by the ongoing instability and volatile political climate that followed the fall of Gadhafi regime. This proof-of-concept study considered employee and managerial perceptions on the organisational culture promoting engagement in four Libyan banks. Specifically, it discusses the disparities between employee and managerial assessment of the key constraints to engagement and organisational culture at the workplace. The study identifies eleven areas of interest for the Libyan banks that are of concern including cooperation, corruption, experience, health, leadership, motivation, nepotism, teamwork, technology, training, and trust. The findings will be used to formulate new theory, determine key research themes, and refine the research agenda for an extended study.
\end{abstract}

Key Words: Employee Engagement, Organisational Culture.

\section{INTRODUCTION}

The Libyan banking sector is currently facing huge challenges following the political chaos that ensued after the overthrow of Col. Muammar Gadhafi's regime in 2011. Because Libyan banking institutions are government controlled, instability in political leadership is likely to lead to greater destabilisation in the way they operate. Thus managers and chief executives need to adopt measures and practices that can get the best out of their subordinates in light of the prevailing circumstances. Such measures should take into consideration the relationship between employees themselves as well as their relationship with the external environment and circumstances in which they operate. Since the banking sector in Libya is not as advanced as that of many developed countries, any efforts to leverage engagement of staff in establishing a successful organisation culture is of particular importance (El-Katiri, 2012).Organisational culture is a vital element in determining how well new employees integrate into their corporate environments which in turn governs their wellbeing and that of their organizations (Nazir, 2005; Silverthorne, 2004). The concept of organisational culture has been defined in many ways by different scholars. According to Hellriegel et al. (2004), organisational culture is "a pattern of shared values and assumptions that guide the activities of a society, including use of language, symbols, narratives and ceremonies." Rowe et al. (1994) propose that organisational culture is "an amalgam of communal beliefs, attitudes, values, norms, assumptions, and expectations of the people within the organisation". On the other hand, Deal \& Kennedy (1982) define it as "an integrated pattern of human behaviour that includes thought, speech, action and artefacts and depends on man's capacity for learning and transmitting knowledge to succeeding generations"(Deal \& Kennedy, 1982).

However, a widely used definition of organisational culture is that advanced by Schein (1984) (Schein, 1984) which defines it as "a pattern of shared basic assumptions that the group learned as it solved its problems of external adaptation and internal integration, that has worked well enough to be considered valid and therefore, to be taught to new members as the correct way to perceive, think, and feel in relation to those problems." Schein's definition draws attention to two fundamental hurdles that a social unit must overcome as times goes on: Firstly, it must be able to adapt to changing conditions outside itself and, secondly, it must integrate newcomers into the unit to maintain it as a functioning entity. Thus, according to Schein, overcoming these twin challenges, one external and the other, internal, is what gives rise to organisational culture through communal learning and the establishment of a distinct set of values, practices, and beliefs (Schein, 1984). Other definitions of organisational culture have been advanced by Hofstede (Hofstede, 1980, 1984, 1991) who suggests that it is "a set of shared values, beliefs, assumptions and practices that shape and guide members' attitudes and behaviour in the organisation". 
Organisational culture is critical to organisational success, and effective leadership provides an important means by which the culture can be created, managed, and sustained (Jamal Mohamed Twati, 2006; Jamal Mohamed Twati \& Gammack, 2006). Understanding the organisation's culture is a crucial aspect of a manager's role within an organisation, since it affects strategic development, productivity and learning at all levels of management (Schneider, 2000). There is common agreement among scholars that the nature and type of culture within an organisation strongly affects employee engagement and therefore organisational productivity (Denison, 1990; Wilkins \& Ouchi, 1983). An organisation's culture acts as a moderating factor in the adoption of new systems and technologies at the workplace (Abdul Rashid, Sambasivan, \& Abdul Rahman, 2004; Fey \& Denison, 2003). Studies to measure employee engagement may sometimes produce conflicting results depending on the model around which designs of such studies are based. Measuring employee engagement must therefore take into account a number of variables, both external and internal, including those related to national and organisational culture.There are a number of models proposed by various scholars that can be used to evaluate organisational culture but the most popular ones are those that have been developed by Schein (Schein, 1985) and Denison (Denison \& Mishra, 1995). The Schein model (1985) is based on three traits of organisational culture which are artefacts, espoused values and shared tacit assumptions. Schein argues that to understand the culture of organisations, these traits need to be evaluated (Schein, 1985). However this model was later amended by Denison (1995) (Denison \& Mishra, 1995) who developed the concept in his own fourtrait model that expanded on Schein's (1985) "espoused values" traits (Denison \& Mishra, 1995). Denison's model provides a link between management of an organization and how it performs in turn. It examines the various determinants of organizational effectiveness, implying that it is best suited for evaluating the impact of organizational culture on the effectiveness of a business. The model is based on the "three levels model" of Schein (1985) but only focusses mainly on the second level which concerns "espouse values" of an organisation. Thus Denison suggests that the performance and effectiveness of an organisation is dependent on four cultural traits, namely: adaptability, mission, consistency and involvement, and therefore any assessment of the effect of organisational culture on organisational performance needs to be able to measure these traits (Denison Consulting, 2015). These traits ensure that the organisation is stable, yet flexible enough to adapt to its environment; is internally coherent, yet externally relevant (Denison Consulting, 2015). This model is useful in exploring employee engagement in relation to the culture within the banking sector.

Libya's culture is traditional characterised by high contact between members of same gender but with minimal interaction between opposite sexes and cultural values are deeply rooted in the religion of Islam (Samovar \& Porter, 2004). Additionally, Libyan organisations have been characterised according to Hofstede's model as having hierarchies with top-down autocratic management approaches as being less individualistic but more team-oriented, being neither feminine nor masculine, having a rigid and inflexible in relation to change, being non-pragmatic and short term oriented, and having an indulgent culture (Crawley, Swailes, \& Walsh, 2013; Hofstede, 2015; Lockwood, Winslow, \& Rambach, 2013).

Macey and Schneider (2008) (Macey \& Schneider, 2008) observe that employee engagement is a combination of both employee attitudes and behaviour, stating that it is "a desirable condition, has an organisational purpose, and connotes involvement, commitment, passion, enthusiasm, focused effort, and energy." This concept has been a subject of growing interest among various scholars for instance, RobertsonSmith \&Markwick (2009) (G. Robertson-Smith \& Markwick, 2009) have shown that engagement is different from other concepts such job satisfaction, organisational commitment, job involvement, organisational citizenship behaviour and motivation. They noted that "despite engagement showing many shared characteristics with existing concepts, there are distinct elements that make the concept unique" (G. RobertsonSmith \& Markwick, 2009). In general employee engagement is recognised to have significant impact in promoting organisational performance leading to improved profitability and growth, especially during period of economic turmoil (Wyatt, 2008) (Wyatt, 2008). However, this concept still lacks sufficient application in the context of the Arab Islamic world where organisational culture tends to be unique due to the unique sociocultural dynamics highly dependent on the Islamic religion, in comparison to the western world (Abukhzam \& Lee, 2010; Rabaa'i, 2009; Rabaai, 2009; Jamal Mohamed Twati, 2006; Jamal M Twati, 2014).Assessment of employee engagement may employ either quantitative or qualitative methods although Robertson-Smith and Markwick (2009: 55) suggest that the latter are more beneficial in exploring the role that managers can play in engaging staff to embrace organisational goals and targets (Gemma Robertson-Smith, 2009).A review of literature on the banking sector in Libya shows that there has been a great deal of research around organizational culture, ethical workplace climate and employee engagement (Bass \& Avolio, 1993; Cameron \& Quinn, 2006; Harter, Schmidt, \& Keyes, 2003; Martin \& Cullen, 2006; Victor \& Cullen, 1988). However, there has not been any detailed research which focuses on employee engagement despite the fact that the 'people factor' is of central importance in organizational performance. Therefore this research aims to identify the factors that influence employee engagement and organisational culture using tools specially designed based on Schein's (1985) model of organisational culture (Schein, 1985). This paper reports the 
preliminary findings based on a pilot study involving employees and managers in selected Libyan banks. These findings might be used to develop a staff engagement framework which can be employed to facilitate employee engagement and leveraging of organizational culture in the Libyan banking sector.

\section{METHODOLOGY}

\subsection{Study design}

Qualitative data was collected from four banks (anonymised as A to D) whose headquarters were based in the Libyan capital, Tripoli. The city was selected as the research area due to its convenient location relative to the researcher. At each of the banks, in-depth interviews were conducted with the manager and one regular employee except in bank D where an interview with the manager could not be obtained. The employees who participated in this study were selected in no particular order from among the staff on duty that day. The interviews employed semi-structured questions by asking the participants: (1)What, in your opinion, is an example of where employee engagement worked well? and (2) What, in your opinion, is an example of where employee engagement did not work as effectively? These questions were used to obtain some understanding of the respondents' points of view rather than to make generalisations about their behaviour. We sought participant's personal opinions about the working environment in order to gather as much data as possible regarding the factors that enabled or inhibited engagement, and were essential in establishing the organisational culture in each facility. Given that the questions were open-ended, further clarifications were sought based on issues arising from the interview until saturation was attained. Rather than base interview questions on a literature search, a Grounded Theory approach (Glaser \& Strauss, 1967) (B. Glaser \& Strauss, 1967; B. G. Glaser \& Strauss, 2009) was employed. The intent was to develop inductive theoretical analyses about organisational culture and employee engagement at the institutions. The questions were used to obtain some understanding of the respondents' points of view rather than to make generalisations about their behaviour. We sought participant's personal opinions about the working environment in order to gather as much data as possible regarding the factors that enabled or inhibited engagement, and were essential in establishing the organisational culture in each facility. Given that the questions were open-ended, further clarifications were sought based on issues arising from the interview until saturation was attained. Permission was sought in advance of each interview and explicit informed consent was obtained.

\subsection{Data analysis}

After every interview the content of the recording was transcribed from audio into text form as soon as possible. In addition, any notes taken during the interview which were thought important in facilitating the researcher's understanding of what was said as opposed to what was meant were transferred onto the transcript along with any audible elements such as emphasis or laughter which added extra sense to the meaning of what was said (Weiss 1994).

\subsubsection{Coding by fragmenting}

The aim of this first analysis in the context of the open coding process is to begin to develop categories and to attempt to label them with the most appropriate codes. The fundamental intention is to try firstly to understand what the interviewee is saying, paying close attention to any possible difficulties and inconsistencies and eventually to interpret the core messages of the interview and formulate codes which can be attached to these.

An initial coding of the text of each transcript was used which involved two basic types of activities intended to produce comparisons. The first of these involved fragmenting and the second connecting but in fact these two activities are intrinsically interconnected and necessary to ensure a balanced result (Boeije 2002).

The process of fragmenting involves identifying the various themes or issues which emerge during the course of an interview. These fragments are then coded usually with a key word or phrase which captures their essence. When these individual key words or phrases are extracted from the context of the original interview as a whole they can then be compared within or across groups, to provide group profiles and can be linked to research questions which may arise. When each of the transcripts had been fragmented, a profile of these keyword segments was produced for each interviewee on an Excel spreadsheet and the totals recorded for each transcript. Totals were also produced across all three manager transcripts and for all four employees. These totals were used as a rough guide for facilitating the ranking of frequencies of keywords and for initial comparisons of employee and managerial profiles. This allowed the researcher to identify some initial themes to be explored. This exercise also revealed that it would prove difficult to code keywords or concepts as being either exclusively inhibitors or enablers, since although it was hoped the two questions would elicit responses which would facilitate this process, responses were often worded in a way which made straightforward categorisation impossible. 
The totals for each of the keywords/phrases from both managers and employees were added together and these were then ranked to create Table 5.3 which revealed four clusters. It is clear that safety and security concerns far outweigh any other category and reflect the situation which prevailed in post-revolutionary Tripoli when this research was conducted where gun-carrying had become prevalent amongst all sectors of society and opportunistic crimes such as robbing customers who had withdrawn money from banks were fairly commonplace:

Everyone working in a bank here [TRIPOLI] worries constantly about security and that makes it a difficult job to do. There's so many incidents with guns. I know my parents worry about my security too. They don't think it's safe for me to work here anymore. (AE)Every day there's another case in the newspapers, a news item on the $T V$. Someone leaving a bank gets targeted by criminals. Some customers are so worried about their safety they're keeping their money at home so they don't have to carry money to or from the bank. (DE)

Table 2.1 Ranking of words/concepts by frequency of occurrence

\begin{tabular}{|l|c|}
\hline Safety \& security & 106 \\
\hline Teamwork & 68 \\
\hline Technology & 68 \\
\hline Training & 67 \\
\hline Cooperation & 65 \\
\hline Experience & 63 \\
\hline Leadership & 50 \\
\hline Nepotism & 18 \\
\hline Corruption & 18 \\
\hline Trust & 15 \\
\hline
\end{tabular}

The next cluster in the ranking is fairly diverse, covering teamwork, technology, training, cooperation and experience and the totals mask the fact that later analysis showed considerable difference in emphasis between employees and managers on the extent to which these affected levels of engagement positively or negatively.

Leadership is the only item in the third cluster and as with the previous cluster, later analysis showed a major difference in how this was ranked by employees and managers, with the former seeing this as playing an important role in encouraging staff engagement:Every large organization needs a leader. Someone who's steering where the company's heading. Everyone feels happier if they know who's behind the wheel.(DE)

This initial coding also confirmed that the frequency with which a particular term was used did not necessarily correspond with the importance that a concept appeared to be given by interviewees. Both 'nepotism' and 'corruption' were both in the final cluster because interviewees made relatively little direct mention of these specific words meaning they both registered a low frequency of use on the keyword/phrase ranking. Managers appeared uncomfortable talking about these types of behaviour and did not wish to be more explicit, even though the researcher tried to encourage them to elaborate. All of the employees, however, talked at length and with considerable feeling about practices which could be construed as instances of nepotism or corruption but they used humorous or euphemistic expressions to talk about both these issues, or made passing comments, meaning that the researcher was left to draw his own conclusions. However, the emphatic hand gestures and tone of voice used by employees made it clear that despite the apparent levity with which they were mentioned, these issues were viewed as being extremely important factors in terms of inhibiting employee engagement.

A queue of 30-odd customers, most of them waiting there already for 30 minutes because two of the cashiers have decided to take the day off again - but they're both cousins of the big boss so hardly surprising. (AE) You don't need experience or qualifications to get a job here. Just a friend upstairs [INDICATES SENIOR

MANAGEMENT OFFICE] (DE) customers. $(A E)$

Everyone knows that managers get a special commission for being extra helpful to certain This initial phase of comparison also functioned as a useful means of quickly establishing frequent words and phrases which were used to start building an initial Arabic-English glossary of recurring keywords and concepts to help with standardization for translation purposes. This linguistic exercise also began to reveal potential gaps where a concept in Arabic did not map directly onto an English equivalent, for example, wasta which is translated for convenience here as 'nepotism', was used with different shades of meaning by interviewees. It also overlapped with concepts such as 'cooperation' (reciprocity between colleagues) in a positive sense and 'corruption' in a negative sense. This linguistic activity began to reveal some interesting results which have 
implications for how categorization is addressed in the main study and this will be discussed in more detail in Chapter Six.

\subsubsection{Coding by connecting}

The second activity of connecting involves comparison between interviewees and seeks to focus on how various groupings ranked keywords. The comparison in this step is between interviewees within the same grouping because they share the same experience, either within each bank as an organization or within a particular role in that organization as employees or managers. The analysis begins with the intrabank comparison. Since there was no managerial interviewee for Bank D, only three ranking profiles are discussed here. The emphasis is on drawing key similarities and differences in employee and managerial opinions.

\subsubsection{Intrabank analysis: bank $A$}

As Table 5.4 illustrates, both AE and AM rank safety and security as the key concern that acts as an inhibitor preventing engagement. It is also striking that both employee and manager also linked this point to its impact on customers, which was also stressed by other interviewees. Whilst in several cases a link was clearly made between staff concerns that customers would be deterred from depositing cash and the potential impact of this on the banking sector, there were also indications, as in this example, that staff genuinely care about customer safety and the bank's reputation:Can you imagine if one of our customers get attacked outside the bank? Or even inside the bank? What would that say about the level of security here? (AE)

There is a neat reversal in the AE and AM rankings for leadership and technology with the employee actually linking these two elements together: All the manager ever talks about is e-banking. And how it will change our lives, our jobs will be so much easier, and this and that. But really, he hasn't got a clue. The Techno Twins, that what we call our IT guys, they fool with him all the time. Sending out information in English he can't read. I don't know much about e-banking but unless technology is part of a big plan and there is a leader who is guiding that plan, how will that change anything for staff? (AE)Staff need new technology. E-banking is where we go next. E-banking is the future. Staff are unhappy because the technology they have doesn't work. They complain all the time. So e-banking-that's what we need to engage staff here. (AM)

As noted previous, although the actual words 'nepotism' and 'corruption' were rarely mentioned, AE clearly viewed elements of these practices as significant disincentives to engagement by the employee whilst the manager hardly referred to them at all:

I worked hard to get a degree but it's not what you know here, it's who you know. It's frustrating knowing that I'm better qualified than most of the managers. (AE)

\begin{tabular}{llll} 
Table 2.2: Factors affecting employee engagement according to bank A interviewees \\
\hline FACTORS & AE & FACTORS & AM \\
\hline Safety \& security & $\mathbf{1 6}$ & Safety \& security & 15 \\
Experience & 11 & Cooperation & 14 \\
Leadership & $\mathbf{1 0}$ & Technology & 13 \\
Training & 10 & Teamwork & 10 \\
Cooperation & 9 & Training & 7 \\
Teamwork & 8 & Experience & 4 \\
Technology & 7 & Leadership & 3 \\
Nepotism & 5 & Corruption & 1 \\
Trust & 5 & Nepotism & 0 \\
Corruption & 4 & Trust & 0 \\
& & & \\
\hline
\end{tabular}

\subsubsection{Intrabank analysis: bank $B$}

As previously safety and security was seen as the key inhibitor for staff engagement by the employee and the manager also acknowledged this but did not give it the same prominence. In this case, the interviewee spoke at great length about safety and security as a result of a recent incident and emphasised how the lack of protection for staff from aggressive and intimidating customers left them feeling undervalued:

Luckily, the guy didn't use his gun but he had it there. He could have used it. We're facing this kind of security threat all the time but we don't get any bonus for putting up with it; we don't even get a thank you. (BE)

There are clear divergences in the keyword ranking between the perspectives here. BM identified problems with technology which was constantly breaking down and out of date as an issue which led to disengagement amongst younger staff: 
The newer employees are used to new technology. Older staff don't care-they still remember paper ledgers. But younger employees- when they can't access spreadsheets on-screen, they get really frustrated and complain a lot. $(B M)$

Table 2.3: Factors affecting employee engagement according to bank B interviewees

\begin{tabular}{llll}
\hline FACTORS & BE & FACTORS & BM \\
\hline Safety and security & 19 & Technology & 13 \\
Experience & 13 & Teamwork & 12 \\
Leadership & 11 & Safety and security & 11 \\
Training & 10 & Cooperation & 9 \\
Teamwork & 10 & Training & 7 \\
Technology & 8 & Experience & 5 \\
Nepotism & 7 & Trust & 3 \\
Cooperation & 6 & Leadership & 1 \\
Corruption & 5 & Nepotism & 1 \\
Trust & 0 & Corruption & 0 \\
\hline
\end{tabular}

BE talked about experience and linked this both positively and negatively to engagement:

Some of the older staff have years of experience but they've been in the same position. A cashier for 25 years... Some are really dedicated - they actually like the routine of the job - but others are just waiting to get a pension. To keep me engaged I need experience of different roles, variety, challenge... but how will I get to be a manager when at the end of the day experience doesn't really count? [SHAKES HEAD] It's more important to have friends in high places. (AE)

As previously mentioned, although the word 'nepotism' is not mentioned, this is clearly implied.

In this case, too, the employee stressed the need for leadership (strong management) to engage staff:I think employees need strong management to get the most out of them, to make them work together, pull together in one direction. Most managers here are weak. They shout, make threats, lots of noise and fuss, to show you they're in charge; that's not strong management. (BE)

\subsubsection{Intrabank analysis: bank $C$}

As with previous banks, safety and security ranked highly but the noticeable difference here was the relative ranking given to technology and teamwork by employee and manager. CE thought technology was the main reason for disengaged staff and explained that the current situation was having a double detrimental effect on engagement:

The biggest source of frustration for workers here at the moment is technology. For younger staff, the IT system seems old, internet access is slow or non-existent and they compare with what they know exists elsewhere and they feel demotivated. For older staff, and that includes a lot of managers, computers are threatening. Their experience and knowledge used to be valued but now they feel it's a big change that they haven't been prepared for. (CE)

In the case of the manager, he placed a big emphasis on teamwork and saw himself as playing a central role in teambuilding:

I get everyone here to work in teams. Everyone has strengths and weaknesses so I allocate roles on the basis of individual skills. Then everyone works together. If people don't get on together I tell them "learn to work together". People like to feel part of a team. It improves job satisfaction. (CM)

The employee perspective was somewhat different:

Last year, we got reorganised into teams but it means nothing. The manager says: " $X$ is good at attention to detail. Give all the end of day totals to him". So that's all X does. He says "This is my role in the team". He doesn't help out with other things. That's not teamwork. It doesn't give me any job satisfaction to feel I'm stuck in one role. $(C E)$ 
Table 1: Factors affecting employee engagement according to bank $\mathrm{C}$ interviewees

\begin{tabular}{llll}
\hline FACTORS & CE & FACTORS & CM \\
\hline Technology & 14 & Safety and security & 16 \\
Safety and security & 13 & Teamwork & 13 \\
Training & 12 & Experience & 12 \\
Leadership & 8 & Cooperation & 10 \\
Experience & 8 & Training & 8 \\
Teamwork & 7 & Leadership & 5 \\
Cooperation & 6 & Technology & 4 \\
Nepotism & 3 & Corruption & 2 \\
Corruption & 3 & Trust & 1 \\
Trust & 0 & Nepotism & 0 \\
\hline
\end{tabular}

This analysis provides an insight into the interaction between employees and managers at each bank and the similarities and differences in their respective perspectives, what they see as issues and agreement or disagreement on relevant themes.

\subsection{Interbank analysis: employees}

At the next stage of comparison, factors were ranked for employees and then for managers, to highlight any major differences and similarities across banks and also to assess if there was agreement about the relative importance of various factors. This process also helps to clarify more about what is understood by the various keywords and concepts and the extent to which they may vary amongst individuals and groupings. Some general observations are useful before more in-depth exploration of some key areas. The single factor that was most commonly referred to by both employees and managers as being important in encouraging employee engagement was 'Safety and security'; the implication being that not enough was being done to provide security for front-of-house staff from the various threats that they faced. 'Teamwork' and 'cooperation' were cited more frequently by managers, probably because the outcomes of good teamwork and cooperation are more significant from the point of the manager than the employee. Conversely, the term 'leadership' (strong management) was given much more importance in terms of engagement during the interviews with employees than with managers. Although as previously explained, 'nepotism' and 'corruption' ranked low in terms of actual mentions of these keywords, both were identified as inhibitors for engagement far more often by employees than by managers. The reasons for this discrepancy and what it implies for the culture of the workplace will be investigated further during the main studyThe responses in connection with 'technology' as a factor were inconsistent. At both Bank $\mathrm{A}$ and Bank B, this factor was mentioned infrequently by the employees but was important to the managers. The situation was exactly reversed in the case of Bank $\mathrm{C}$. Why this should be so is not clear and will require further investigation in the full study.

The fact that the lack of availablity of training was mentioned as a factor in all the banks significantly more by employees than by managers suggests that employees may feel frustrated by the current lack of opportunities and cited this lack of opportunities to increase their knowledge and skills and improve their future career as a reason for a lack of engagement. With regard to experience and trust, the results were inconsistent in that employees in banks A and B referred to experience far more than did their managers; however, in the case of bank $\mathrm{C}$ the situation was reversed. Similarly, the issue of trust was raised several times by the employee at bank A but not all by the employees at banks B and C. The manager at bank A did not mention this factor at all, unlike the managers at the other banks who brought up the subject on several occasions. In Tables 2.5 and 2.6, keywords shaded in grey indicate that this was ranked similarly by three interviewees within a grouping. Bolded keywords shows that two interviewees ranked this similarly. The general pattern that emerges is that employees seem to have a more unified opinion on the ranking of importance of factors, although admittedly this does not tell us about whether they class these as inhibitors or enablers since analysis of individual interviews suggests that in a number of cases factors were viewed in both positive and negative terms.

Table2.5: Factors affecting employee engagement according to employees

\begin{tabular}{|c|c|c|c|c|c|c|c|c|c|c|}
\hline FACTORS & $\mathbf{E}$ & A & FACTORS & $\mathbf{E}$ & FACTOR & & $\mathbf{E}$ & FACTOR & & $\mathbf{E}$ \\
\hline $\begin{array}{cc}\text { Safety } & \& \\
\text { security } & \end{array}$ & 6 & 1 & $\begin{array}{l}\text { Safety } \\
\text { security }\end{array}$ & 9 & Technolog & & 4 & $\begin{array}{l}\text { Safety } \\
\text { security }\end{array}$ & $\&$ & 6 \\
\hline Experience & 1 & 1 & Experience & 3 & $\begin{array}{l}\text { Safety } \\
\text { security }\end{array}$ & $\&$ & 3 & Training & & 3 \\
\hline Leadership & & 1 & Leadership & 1 & Training & & & Leadershi & & 1 \\
\hline
\end{tabular}


Factors Influence Employee Engagement Leveraging by

\begin{tabular}{|c|c|c|c|c|c|c|c|c|c|c|}
\hline & & 0 & & & 1 & & & & & 2 \\
\hline \multirow{8}{*}{$\mathrm{n}$} & Training & 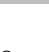 & 1 & Training & & 1 & Leadership & 8 & Cooperation & 1 \\
\hline & & 0 & & & 0 & & & & & 1 \\
\hline & Cooperatio & & 9 & Teamwork & & 1 & Experience & 8 & Experience & 1 \\
\hline & Teamwork & & 8 & Technology & 0 & 8 & Teamwork & 7 & Technology & 9 \\
\hline & Technology & & 7 & Nepotism & & 7 & Cooperation & 6 & Teamwork & 8 \\
\hline & Nepotism & & 5 & Cooperation & & 6 & Nepotism & 3 & Trust & 6 \\
\hline & Trust & & 5 & Corruption & & 5 & Corruption & 3 & Corruption & 3 \\
\hline & Corruption & & 4 & Trust & & 0 & Trust & 0 & Nepotism & 2 \\
\hline
\end{tabular}

Table 2.6: Factors affecting employee engagement according to managers

\begin{tabular}{|c|c|c|c|c|c|c|c|c|}
\hline FACTORS & & $\mathbf{M}$ & $\mathbf{A}$ & FACTORS & M & B & FACTORS & $M^{C}$ \\
\hline Safety & $\&$ & & 1 & Technology & & 1 & Safety & 1 \\
\hline security & & 5 & & & 3 & & security & 6 \\
\hline Cooperation & & 4 & 1 & Teamwork & & 1 & Teamwork & $3^{1}$ \\
\hline Technology & & 3 & 1 & Safety and security & & 1 & Experience & 2 \\
\hline Teamwork & & 0 & 1 & Cooperation & & 9 & Cooperation & 0 \\
\hline Training & & & 7 & Training & & 7 & Training & 8 \\
\hline Experience & & & 4 & Experience & & 5 & Leadership & 5 \\
\hline Leadership & & & 3 & Trust & & 3 & Technology & 4 \\
\hline Corruption & & & 1 & Leadership & & 1 & Corruption & 2 \\
\hline Nepotism & & & 0 & Nepotism & & 1 & Trust & 1 \\
\hline Trust & & & 0 & Corruption & & 0 & Nepotism & 0 \\
\hline
\end{tabular}

\subsection{Mapping concepts}

Once the ranking of key words had been established, further comparative analysis was carried out to try and establish more about the meanings that these terms had for interviewees by examining the contexts in which they used these words.

\subsubsection{Safety/security}

For all interviewees, whether front-of-house employees or middle management, these terms were equated to problems they were facing on a daily basis generally as a result of previous and post-revolutionary conflict within Libya which had produced an unsafe workplace where they felt there was a lack of protection for both staff and customers. They were related most commonly to a broad spectrum of concerns for personal safety ranging from having to deal with irate customers and face overt displays of aggression which involved behaviour such as shouting, violent gestures and verbal threats, to the less overt but much more threatening awareness of the weapons being carried by many of the customers entering the bank. All interviewees had experience of customer aggression at first or second hand, although cashiers were the most exposed. It is worth noting that cashiers in Libyan banks have no form of protection between them and the public since counters are still totally open.

\subsubsection{Teamwork}

One of the most revealing extracts regarding how this usually positive enabler for engagement could be viewed as an inhibitor can be found in two accounts of what teamwork meant to a manager and the employee. The manager was convinced that his innovation of getting everyone at the bank to work in teams was improving job satisfaction but for a number of reasons this had clearly not worked as an enabler for the employee for whom teamwork means people can work in areas where they have strengths but they must also be able and willing to play other roles. This employee was clear that just because the manager calls a group a employees a team, this does not make them a successful or effective team but a group of individuals with specialist 
skills.Katzenbach and Smith (1993) highlighted that successful teamworking required not only individuals with complementary skills but also a commitment to achieving a common purpose or goal, which needed to be known by all members of the team. The concept of teamwork can be usefully compared and contrasted with cooperation.

\subsubsection{Cooperation}

According to Johnson, Johnson, and Holubec (1998), cooperation can be viewed as an element of teamwork and usually implies working together to accomplish a shared goal, with individuals seeking outcomes that are beneficial to themselves and to all other group members. Bank employees seemed to take a narrower view of this concept, seeing it in terms of a reciprocal agreement entailing mutual support between two individuals which did not usually involve benefit to others in the workplace as the following extract shows:

I know my colleague $X$ really well- we come from the same neighbourhood, went to the same university. So we always cooperate with each other. For example, last week, my wife was in hospital. I needed to collect my son from school, so X cashed up for me so I could get away early. He knows if he needs a favour, I'll always cooperate with him. If more staff would cooperate with each other, the bank would be a better place to work and everyone would engage more. (DE)

Managers tended to view cooperation more in terms of compliance i.e. behaving in the way he wanted, as in this extract:

It's a problem getting some staff to cooperate and I think that shows they're disengaged. I keep telling the two young guys who take care of IT that they must make sure we have instructions available in Arabic as well as English for staff to follow. But they studied in the UK; they read English without problems and don't see why staff can't follow manuals in English: they just refuse to cooperate. (AM)

\subsubsection{Technology}

In this context, technology closely equates with information technology, covering both hardware and infrastructure. Interviewees also judged technology on the basic of how current it was and how accessible to front-of-house employees and customers. One of the issues which the topic of technology highlights is a distinct 'digital gap' between older experienced staff including managers and younger qualified computer-literate staff. This means that technology had a particular relationship with engagement in the contact of the Libyan explored here.For the younger generation technology which does not work, or is considered old is a source of great frustration whereas older staff view computers as a threat to their former authority based on experience and knowledge. This gives this factor a number of dimensions which merit further exploration.

\subsubsection{Training}

Employees used the same word to designate two different but equally important elements. The first involved the induction process, which was necessary to ensure that new staff could perform adequately in the job but the fact that this was not provided seemed to be accepted by employees and was not seen as either an enabler or inhibitor of engagement:

When I started here, I was just shown once how to cash up by one of the other members of staff and then another colleague watched me cash up their till. That was my induction training [LAUGHS] But I have a cousin who works here -he's been here five years and he got me this job-so he told me what I needed to know and I ask him if I need any help.

This quote also illustrates how different types of informal networking play an important role within the Libyan workplace not only in terms of securing a post (nepotism) but also in providing ongoing support for those regarded as protégés. Access to training which provided development of skills and knowledge was viewed as a potential enabler of engagement by employees but they felt that all often it was controlled by managers who allocated training on the basis of favouritism rather than clearly understood criteria.

\subsubsection{Experience}

Interviewees tended to use this term to refer to the time a member of staff had spent working within the bank or within a particular section of the bank. One interviewee suggested that it could be both an enabler and an inhibitor of engagement depending on the individual. He noted that there were different types of older bank staff with experience: "Some are really dedicated - they actually like the routine of the job - but others are just waiting to get a pension" (BE) suggesting very different levels of engagement. This interviewee saw experience as meaning "different roles, variety, challenge" and that this would be an enabler of engagement. 


\subsubsection{Leadership}

Yuki's (2006: 8) definition seemed to match the elements which were highlighted by interviewees: "the process of influencing others to understand and agree about what needs to be done and how to do it, and the process of facilitating individual and collective efforts to accomplish shared objectives".

When managers referred to leadership, they tended to talk about this as a function of senior management or senior executives but did not see it as being a strong enabler of engagement. Employees, however, drew clear distinctions between leaders and managers in terms of their qualities and their ability to impact positively on staff engagement. Employees tended to refer to leadership as 'strong management'.

We need some strong management and that has to come from the top. We need some sense of direction. We just go from day to day in this bank. We're like a ship in the middle of the ocean - we drift along... and the managers here- they don't have what it takes to be a captain! (AE)

Every large organization needs a leader. Someone who's steering where the company's heading. Everyone feels happier if they know who's behind the wheel.(DE)

I think employees need strong management to get the most out of them, to make them work together, pull together in one direction. Most managers here are weak. They shout, make threats, lots of noise and fuss, to show you they're in charge; that's not strong management. (BE)

Engagement was strongly linked to knowing what the organization was trying to achieve (sense of direction, pull together in one direction) and having a strong figurehead. Research suggests that a key element in engaging employees is encouragement from managers (CIPD 2006:31). There was the strong impression during the interviews that employees felt they were not being given sufficiently positive leadership and motivation.

\subsubsection{Trust}

According to Rousseau et al. (1998), trust is usually viewed as the level of confidence an individual has in both the intentions of those around them and their abilities. Although trust was mentioned infrequently, both these dimensions also featured in the understanding of this concept amongst participants:

I trust my family and my friends but not the management. They're here to get what they can from the system. $(A E)$

When the manager says we can't do anything about an IT problem, I don't trust his opinion. He's got no idea about IT. (AE)

\subsubsection{Nepotism (wasta)}

In the context of this study, interviewees used the Arabic word 'wasta' which for the purpose of convenience here has been translated as 'nepotism'. However, as Barnett, Yandle and Naufal (2013: 2) note:

For those who work and live in Middle Eastern societies, "wasta," which may be thought of as special influence enjoyed by members of the same group or tribe, is an ever-present part of life [...] deeply embedded in the fabric of these societies.In the title of their book-length study of wasta, Cunningham and Sarayrah (1993) referred to it as "The Hidden Force in Middle Eastern Society". According to Barnett et al. (2013:2), wasta is often linked with cronyism and corruption generally in Western academic literature but they acknowledge that it is viewed differently in Arab societies: Wasta $[\ldots]$ refers to an implicit social contract, typically within a tribal group, which obliges those within the group to provide assistance (favourable treatment) to others within the group. Members of the group have a largely unqualified obligation to provide assistance when asked, and those who ask for assistance have no obligation to provide direct compensation for assistance provided.

In Libyan society, being able to request assistance from someone in a position of power in obtaining employment is not viewed as being unacceptable and one of the interviewees openly spoke about getting his present post in the bank due to a "cousin who works there" (CE).

In their study, Mohammad and Hamdy (2008: 1) examined the effect of wasta in the context of employment and found that "unqualified candidates obtaining jobs solely on the basis of influence or connections has created an environment that continues to feed frustration among qualified and well skilled individuals". This was clearly reflected in the interviews and was perceived as providing undeserved advantages based on connections instead of merit:

I worked hard to get a degree but it's not what you know here, it's who you know. It's frustrating knowing that I'm better qualified than most of the managers. (AE)

but how will I get to be a manager when at the end of the day experience doesn't really count? [SHAKES $H E A D]$ It's more important to have friends in high places. (AE)

You don't need experience or qualifications to get a job here. Just a friend upstairs [INDICATES SENIOR 
In addition, there was also evidence that employees felt that wasta was a source of unequal treatment creating resentment:

two of the cashiers have decided to take the day off again - but they're both cousins of the big boss so hardly surprising. $(A E)$

In terms of engagement, this was clearly seen a major inhibitor and given the importance of wasta within Libyan society, this is an area which merits closer attention in the main study, not least because relatively little has been written to date about this issue

\subsubsection{Corruption}

As with nepotism, although there were few direct mentions of the keyword 'corruption', there were references to different types of illegal activities being carried out within the organisation, including mishandling of funds:

Everyone knows that managers get a special commission for being extra helpful to certain customers.(AE)

Given that staff were often euphemistic or humorous in their references to corrupt practices within the bank, it is difficult to judge the seriousness of the various forms of corruption described but most seemed to be what are usually referred to as facilitation payments (Business Anti-Corruption website). These practices seemed to be less of a concern in terms of inhibiting engagement than nepotism and were viewed as an inevitable fact of life in the public sector.

\subsection{Direct Observation}

In addition to the qualitative data collected during the interviews, the researcher also undertook direct observations that may prove relevant for triangulation purposes, providing an sight into data from interviewees. Safety and security emerged as a serious concern which may have affected engagement. In Bank C, the manager had his office on a separate floor from the employees, meaning he did not see at first hand any of the incidents experienced by front-of-house staff, and although all the banks have security men on duty, Banks C and D had fewer than Banks A and B. Not all the banks have CCTV cameras. Whilst the researcher was in the bank, incidents concerning aggressive customers occurred which suggested that employees would feel threatened within their working environment. Long queues were often visible in the banks, none of which had a system in place to use a member of staff to enquire what those in the queue wanted and to answer any queries which could be dealt with easily. This often led to high levels of frustration amongst customers, increasing the risk of outbursts of anger and displays of aggression.

The researcher's own observations also made it clear that there were problems with technology in all the banks visited; for example, although all the banks did have ATMs for customers, they were often out of operation, adding to the already lengthy queues.

\subsection{Pilot study findings on enablers/inhibitors of employee engagement}

In the pilot study safety and security was identified by employees and managers alike as the single biggest factor most likely to inhibit engagement within the organization. According to Swathls "Research indicates that engagement levels are low if the employee does not feel secure whilst working.Therefore, every organization should adopt appropriate methods and systems for the safety of their employees" (2013: 3 ). It is not wholly clear what form this disengagement takes since it was striking that despite everything, comments were made that suggested despite all the problems faced by frontline staff concern was expressed about customer safety and the reputation of the bank and there were also mentions about dedicated staff and about seeking challenge in the workplace. This points to the fact that there is still some intrinsic motivation driving engagement in certain cases; other staff were highlighting the need for more extrinsic motivation in the form of financial rewards or at very least, acknowledgment by management of a job well done. Research has noted the key role that both types of motivation can play in engagement (Deci \& Ryan, 1985; Robbins 1993).

With regards to line managers, a number of authors have emphasised the key role played by middle management in implementing employee engagement strategies, some concluding that for employees their immediate manager is likely to be more important than any other organisational variable in harnessing the passion and enthusiasm of those whom they manage (Macleod and Clarke, 2009; Wallace and Trinka 2009; Lombardi 2010; CIPD 2006; Dulye 2006; Towers Perrin, 2006; Robinson et al., 2007). Conversely, mismanagement of employees is likely to result in a steady decline in performance (Pfeiffer 1998). In short, an effective manager acts as a strong enabler of employee engagement; a poor line manager inhibits this. It is clear in this study that for a variety of reasons that the relationship between employees and managers in the fours banks considered is poor reflected in comments regarding negative behaviours and practices observed and also reflected in some of the comments made by managers which suggested a lack of competence in dealing with staff (e.g. in facilitating teamwork).Lack of communication with their line manager was viewed as another key inhibitor by employees. Tourish and Hargie (2009), Brockett (2009) and Watson Wyatt (2006) all concluded 
that communication was an important factor in enabling employee engagement. Tourish and Hargie (2009) stress in particular that upward communication lines from subordinates to manager must be kept open and free to ensure employees are kept fully involved. The fact that employees lack access to ICT may also play a role in poor communications within the work environment with Gill (2009), Eunson(2005), Harrison (2007) and Gaither (2012) all agreeing that this represents the most effective and readily available medium for large organisations to communicate with internal stakeholders. ICT could act as a facilitator of employee-line manager communication and in turn improve this relationship, acting as an enabler of engagement. Macleod and Clarke (2009) found that good managers engage staff by finding training that benefits both individual employees and the organization. Employees in this study viewed training which provided development of skills and knowledge as a potential enabler of engagement but raised the issue of the role of the manager as gatekeeper to granting access to such opportunities as problematic since they felt managers allocated training on the basis of favouritism rather than clearly understood criteria linking this to wasta. Employees may feel frustrated by the current lack of opportunities and cited this lack of opportunities to increase their knowledge and skills and improve their future career as a reason for a lack of engagement.Kelly (2001) and Schaufeli and Salanova (2007) conclude that successful engagement within an organisation demands both effective leadership and effective followership. Complaints by line managers about the lack of teamwork and cooperation from bank employees illustrate that their lack of strong management skills had failed to convince staff of their capability. Employees drew attention to the interconnected factors of corruption and nepotism (wasta) in the banks and it was clear that for most employees this was a major issue which acted as a strong inhibitor for engagement, although one happily noted that he owed his current position to this practice. A great deal has been written about these topics within the MENA countries and within Libya specifically, both of which were exacerbated by practices under Gadhafi's regime (U4 Anti-Corruption Resource Centre, 2012). These elements can be seen as core components of the organisational culture within the Libyan banking sector and as such they are likely to affect employee conduct (Tellis et al., 2009), influence and drive employee behaviour and the level of commitment within the workplace(Deal and Kennedy 2008).

\section{REFERENCES}

[1] Abdul Rashid, Z., Sambasivan, M., \& Abdul Rahman, A. (2004). The influence of organizational culture on attitudes toward organizational change. Leadership \& organization development Journal, 25(2), 161179.

[2] Abukhzam, M., \& Lee, A. (2010). Factors affecting bank staff attitude towards e-banking adoption in Libya. The Electronic Journal of Information Systems in Developing Countries, 42.

[3] Alimo-Metcalfe, B., \& Alban-Metcalfe, J. (2009). Engaging leadership: creating organisations that maximise the potential of their people: CIPD.

[4] Ancona, D., Malone, T. W., Orlikowski, W. J., \& Senge, P. M. (2007). In praise of the incomplete leader. Harvard Business Review, 85(2), 92-100, 156.

[5] Barnett, Andy, Yandle, Bruce and Naufal, George (2013) "Regulation, Trust, and Cronyism in Middle Eastern Societies: The Simple Economics of Wasta" Journal of Socio-Economics, 44, 41 - 46

[6] Bass, B. M., \& Avolio, B. J. (1993). Transformational leadership and organizational culture. Public administration quarterly, 112-121.

[7] Cameron, K. S., \& Quinn, R. E. (2006). Diagnosing and changing organizational culture. Revised edition. SF: Jossey-Bass.

[8] Crawley, E., Swailes, S., \& Walsh, D. (2013). Introduction to international human resource management: Oxford University Press.

[9] Deal, T. E., \& Kennedy, A. A. (1982). Corporate cultures: The rites and rituals of organizational life. Mass:: Addison-Wesley.

[10] Deci, E. L., \& Ryan, R. M. (1985a). The general causality orientations scale: Self-determination in personality. Journal of research in personality, 19(2), 109-134.

[11] Deci, E. L., \& Ryan, R. M. (1985b). Intrinsic motivation and self-determination in human behavior: Springer Science \& Business Media.

[12] Denison, D. R. (1990). Corporate culture and organizational effectiveness: John Wiley \& Sons.

[13] Denison, D. R., \& Mishra, A. K. (1995). Toward a theory of organizational culture and effectiveness. Organization science, 6(2), 204-223.

[14] Eastern Societies: The Simple Economics of 'Wasta'. The Journal of Socio-Economics, 44,

[15] pp. 41-46.

[16] Ekvall, G. (1996). Organizational climate for creativity and innovation. European journal of work and organizational psychology, 5(1), 105-123.

[17] El-Katiri, M. (2012). State-building Challenges in a Post-revolution Libya: DTIC Document. 
[18] Fey, C. F., \& Denison, D. R. (2003). Organizational culture and effectiveness: can American theory be applied in Russia? Organization science, 14(6), 686-706.

[19] Gill, J. and Johnson, P. (2002) Research Methods for Managers. London: Paul Chapman.

[20] Glaser, B., \& Strauss, A. (1967). The discovery of Grounded Theory. London: Weidenfeld and Nicholson.

[21] Glaser, B. G., \& Strauss, A. L. (2009). The discovery of grounded theory: Strategies for qualitative research: Transaction Publishers.

[22] Haid, M., \& Sims, J. (2009). Employee engagement: maximizing organizational performance. Leadership Insights.

[23] Harter, J. K., Schmidt, F. L., \& Keyes, C. L. (2003). Well-being in the workplace and its relationship to business outcomes: A review of the Gallup studies. Flourishing: Positive psychology and the life welllived, 2, 205-224.

[24] Hofstede, G. (1980). Culture and organizations. International Studies of Management \& Organization, $15-41$.

[25] Hofstede, G. (1984). Culture's consequences: International differences in work-related values (Vol. 5): sage.

[26] Hofstede, G. (1991). Cultures and Organizations: Software of the Mind. Berkshire, UK: McGraw-Hill.

[27] Hofstede, G. (2015). Strategy, Culture \& Change: What about Libya? Retrieved 28 June, 2015, from http://geert-hofstede.com/libya.html

[28] Lockwood, A. N., Winslow, A., \& Rambach, P. S. (2013). Libya, Building a Desert Economy: International Conciliation, No. 512, March, 1957: Literary Licensing, LLC.

[29] Macey, W. H., \& Schneider, B. (2008). The meaning of employee engagement. Industrial and organizational Psychology, 1(1), 3-30.

[30] MacLeod, D., \& Clarke, N. (2009). Engaging for success: enhancing performance through employee engagement: a report to government.

[31] Martin, K. D., \& Cullen, J. B. (2006). Continuities and extensions of ethical climate theory: A metaanalytic review. Journal of Business Ethics, 69(2), 175-194.

[32] Nazir, N. A. (2005). Person-culture fit and employee commitment in banks. Vikalpa, 30(3), 39

[33] Newnam, J. L. (2014). Defining a Leader.

[34] Newnam, J. L. (2015). From Top to Bottom-A Consultant's View.

[35] Pfeiffer, J. J. (1998). From Performance Reporting to Performance-Based Funding: Florida's Experiences in Workforce Development Performance Measurement. New Directions for Community Colleges, 1998(104), 17-28.

[36] Rabaa'i, A. A. (2009). The impact of organisational culture on ERP systems implementation: lessons from Jordan. Paper presented at the Proceedings of the Pacific Asia Conference on Information Systems 2009.

[37] Rabaai, A. (2009). ERP Systems Implementation and Organizational Culture: The Case of Jordan.

[38] Robertson-Smith, G. (2009). Employee engagement: A review of current thinking: Institute for Employment Studies.

[39] Robertson-Smith, G., \& Markwick, C. (2009). Employee Engagement: A Review of Current Thinking: Institute for Employment Studies.

[40] Robinson, S. L., \& O’Leary-Kelly, A. M. (1998). Monkey see, monkey do:The influence of work groups on the antisocial behavior of employees.Academy of Management Journal, 41, 658-672.

[41] Salanova, M., Agut, S. and Peiro, J.M., 2007.Linking organizational resources and work engagement to employee performance and customer loyalty: the mediation of service climate.Journal of Applied Psychology, 90(6), pp. 1217-1227.

[42] Samovar, L. A., \& Porter, R. E. (2004). Communication between cultures: Wadsworth/Thomson Learning.

[43] Schaufeli, W.B. and Salanova, M., 2007. Work engagement: an emerging psychological concept and its implications for organizations. In: S.W. Gilliland, D.D. Steiner, and D.P.

[44] Schein, E. H. (1984). Coming to a new awareness of organizational culture. Sloan management review, 25(2), 3-16.

[45] Schein, E. H. (1985). Organisational culture and leadership: A dynamic view. San Francisco.

[46] Schneider, B. (2000). The psychological life of organizations. Handbook of organizational culture and climate, $17-21$.

[47] Silverthorne, C. (2004). The impact of organizational culture and person-organization fit on organizational commitment and job satisfaction in Taiwan. Leadership \& organization development Journal, 25(7), 592-599.

[48] Sutton-Smith, B. (2009). The ambiguity of play: Harvard University Press. 
[49] Tellis, G. J., Prabhu, J. C. and Chandy, R. K. (2009) Radical Innovation Across Nations: The Preeminence of Corporate Culture, Journal of Marketing, Vol. 73, p. 3-23.

[50] Tourish,D., Hargie,O. (2009) Communication and organisational success, in Hargie, O and Tourish, D (eds) Auditing Organizational Communication, Hove: Routledge

Twati, J. M. (2006). Societal and organisational culture and the adoption of management information systems in Arab countries. Griffith Business School Brisbane, Australia.

[51] Twati, J. M. (2014). The influence of societal culture on the adoption of information systems: The case of Libya. Communications of the IIMA, 8(1), 1.

[52] Twati, J. M., \& Gammack, J. G. (2006). The impact of organisational culture innovation on the adoption of IS/IT: the case of Libya. Journal of enterprise information management, 19(2), 175-191.

[53] Vallerand, R. J., Pelletier, L. G., Blais, M. R., Briere, N. M., Senecal, C., \& Vallieres, E. F. (1992). The academic motivation scale: A measure of intrinsic, extrinsic, and amotivation in education. Educational and psychological measurement, 52(4), 1003-1017.

[54] Victor, B., \& Cullen, J. B. (1988). The organizational bases of ethical work climates. Administrative science quarterly, 101-125.

[55] Wilkins, A. L., \& Ouchi, W. G. (1983). Efficient cultures: Exploring the relationship between culture and organizational performance. Administrative science quarterly, 468-481.

[56] Wyatt, G. (2008). Family Ties: Relationships, Socialization, and Home Schooling. Maryland: University Press of America, Inc.

[57] Yukl, G. A. (2006). Leadership in Organizations (4th edition). Englewood Cliffs, NJ: Prentice-Hall. 